\title{
Proximal renal tubular acidosis with and without Fanconi syndrome
}

\author{
Ibrahim Kashoor ${ }^{(i)}$, Daniel Batlle ${ }^{\text {(i) }}$ \\ Division of Nephrology and Hypertension, Department of Medicine, The Feinberg School of Medicine, Northwestern University, \\ Chicago, IL, USA
}

Proximal renal tubular acidosis (RTA) is caused by a defect in bicarbonate $\left(\mathrm{HCO}_{3}{ }^{-}\right)$reabsorption in the kidney proximal convoluted tubule. It usually manifests as normal anion-gap metabolic acidosis due to $\mathrm{HCO}_{3}{ }^{-}$wastage. In a normal kidney, the thick ascending limb of Henle's loop and more distal nephron segments reclaim all of the $\mathrm{HCO}_{3}{ }^{-}$not absorbed by the proximal tubule. Bicarbonate wastage seen in type II RTA indicates that the proximal tubular defect is severe enough to overwhelm the capacity for $\mathrm{HCO}_{3}{ }^{-}$reabsorption beyond the proximal tubule. Proximal RTA can occur as an isolated syndrome or with other impairments in proximal tubular functions under the spectrum of Fanconi syndrome. Fanconi syndrome, which is characterized by a defect in proximal tubular reabsorption of glucose, amino acids, uric acid, phosphate, and $\mathrm{HCO}_{3}{ }^{-}$, can occur due to inherited or acquired causes. Primary inherited Fanconi syndrome is caused by a mutation in the sodium-phosphate cotransporter $\left(\mathrm{NaP}_{\mathrm{i}}-\mathrm{II}\right)$ in the proximal tubule. Recent studies have identified new causes of Fanconi syndrome due to mutations in the EHHADH and the HNF4A genes. Fanconi syndrome can also be one of many manifestations of various inherited systemic diseases, such as cystinosis. Many of the acquired causes of Fanconi syndrome with or without proximal RTA are drug-induced, with the list of causative agents increasing as newer drugs are introduced for clinical use, mainly in the oncology field.

Keywords: Acidosis, renal tubular, Drug-induced nephrotoxicity, Fanconi syndrome, Proximal tubular toxicity

\section{Introduction}

Proximal renal tubular acidosis (RTA) as an isolated defect in tubular transport of bicarbonate $\left(\mathrm{HCO}_{3}^{-}\right)$is characterized by a decreased rate of $\mathrm{HCO}_{3}{ }^{-}$reabsorption

\footnotetext{
Received May 21, 2019; Revised June 13, 2019;

Accepted June 19, 2019

Edited by Gheun-Ho Kim, Hanyang University, Seoul, Korea

Correspondence: Daniel Batlle

Division of Nephrology and Hypertension, Department of Medicine, The Feinberg School of Medicine, Northwestern University, $320 \mathrm{E}$ Superior, Chicago, IL 6o611, USA. E-mail: d-batlle@northwestern.edu

Copyright (C) 2019 by The Korean Society of Nephrology

(a) This is an open-access article distributed under the terms of the Creative Commons Attribution Non-Commercial License (http://creativecommons. org/licenses/by-nc-nd/4.0/), which permits unrestricted non-commercial use, distribution, and reproduction in any medium, provided the original work is properly cited.
}

in the proximal tubule in the absence of alterations in the transport of other solutes [1-8]. Unlike in patients with classic distal RTA, patients with proximal RTA are able to lower their urine $\mathrm{pH}$ when plasma bicarbonate falls to a certain level $[4,8]$. Isolated proximal RTA is exceedingly rare, with the exception of the iatrogenic form, which is caused by the use of carbonic anhydrase (CA) inhibitors. Proximal RTA is more commonly associated with generalized dysfunction of the proximal tubule as part of Fanconi syndrome [2-4]. The syndrome is caused by a generalized dysfunction of the reabsorptive capacity of the kidney proximal tubule, causing a loss of solutes, including phosphate, uric acid, glucose, amino acids, lowmolecular-weight proteins, and bicarbonate [9-12].

In recent years, new causes of drug-induced RTA and Fanconi syndrome have been recognized and the mechanisms of the proximal tubular alterations causing Fanconi syndrome are much better understood. In this review, 
we discuss proximal RTA, including the many causes of drug-induced proximal RTA and Fanconi syndrome.

\section{Overview of bicarbonate transport along the nephron}

In an individual with normal plasma $\mathrm{HCO}_{3}^{-}$level and a glomerular filtration rate (GFR) of $100 \mathrm{~mL} / \mathrm{min}, \sim 2,500$ mEq of $\mathrm{HCO}_{3}^{-}$is filtered daily; virtually all of this $\mathrm{HCO}_{3}^{-}$ is reabsorbed so that essentially none appears in the urine $[2,13]$. Bicarbonate is freely filtered by the kidney glomerulus, and its concentration in the glomerular filtrate is equal to that in plasma $(\sim 25 \mathrm{mEq} / \mathrm{L})[2,13]$. The majority $(\sim 80 \%)$ of the filtered $\mathrm{HCO}_{3}{ }^{-}$is reabsorbed in the proximal tubule and the remaining $20 \%$ that escapes reabsorption is reclaimed distally by the thick ascending limb (TAL) of the loop of Henle, distal tubules, and collecting tubules. Because the vast majority of $\mathrm{HCO}_{3}{ }^{-}$ is normally reabsorbed in the proximal tubule, finding a significant amount of $\mathrm{HCO}_{3}{ }^{-}$in the urine is usually taken as evidence of a defect in proximal tubular $\mathrm{HCO}_{3}{ }^{-}$ reabsorption. When there is a major defect in $\mathrm{HCO}_{3}{ }^{-}$ reabsorption in the proximal tubule, a larger quantity of filtered $\mathrm{HCO}_{3}{ }^{-}$is delivered to the distal segments, including the TAL, overwhelming the distal system and causing urinary $\mathrm{HCO}_{3}{ }^{-}$wastage, which is the clinical hallmark of underlying derangement in proximal tubular function.

The mechanisms involved in $\mathrm{HCO}_{3}{ }^{-}$reabsorption in proximal tubular cells are depicted in Fig. $1 . \mathrm{HCO}_{3}{ }^{-}$transport across the luminal membrane does not take place as such; rather it is the result of secretion of $\mathrm{H}^{+}$into the tubular lumen. The filtered $\mathrm{HCO}_{3}{ }^{-}$reacts with the luminal $\mathrm{H}^{+}$, which is secreted mainly by an apical sodium/hydrogen exchanger $3\left(\mathrm{Na}^{+} / \mathrm{H}^{+}\right.$exchanger isoform 3 [NHE3]) (solute carrier 9 A3 [SLC9A3]) [14] and to a lesser extent by an apical vacuolar $\mathrm{H}^{+}$-ATPase [15] to form $\mathrm{H}_{2} \mathrm{CO}_{3}$. This weak acid is readily dissociated into $\mathrm{CO}_{2}$ and $\mathrm{H}_{2} \mathrm{O}$ by a brush border CA. The kidney has at least two forms of carbonic anhydrase, CA II and CA IV [16]. CA II is found in the cell cytoplasm of both proximal and distal tubules and is also present in red blood cells, whereas CA IV is found mainly in the brush border of the proximal tubule. The latter is the isoform of CA involved in facilitating apical $\mathrm{HCO}_{3}{ }^{-}$reabsorption in the proximal tubule. It per-

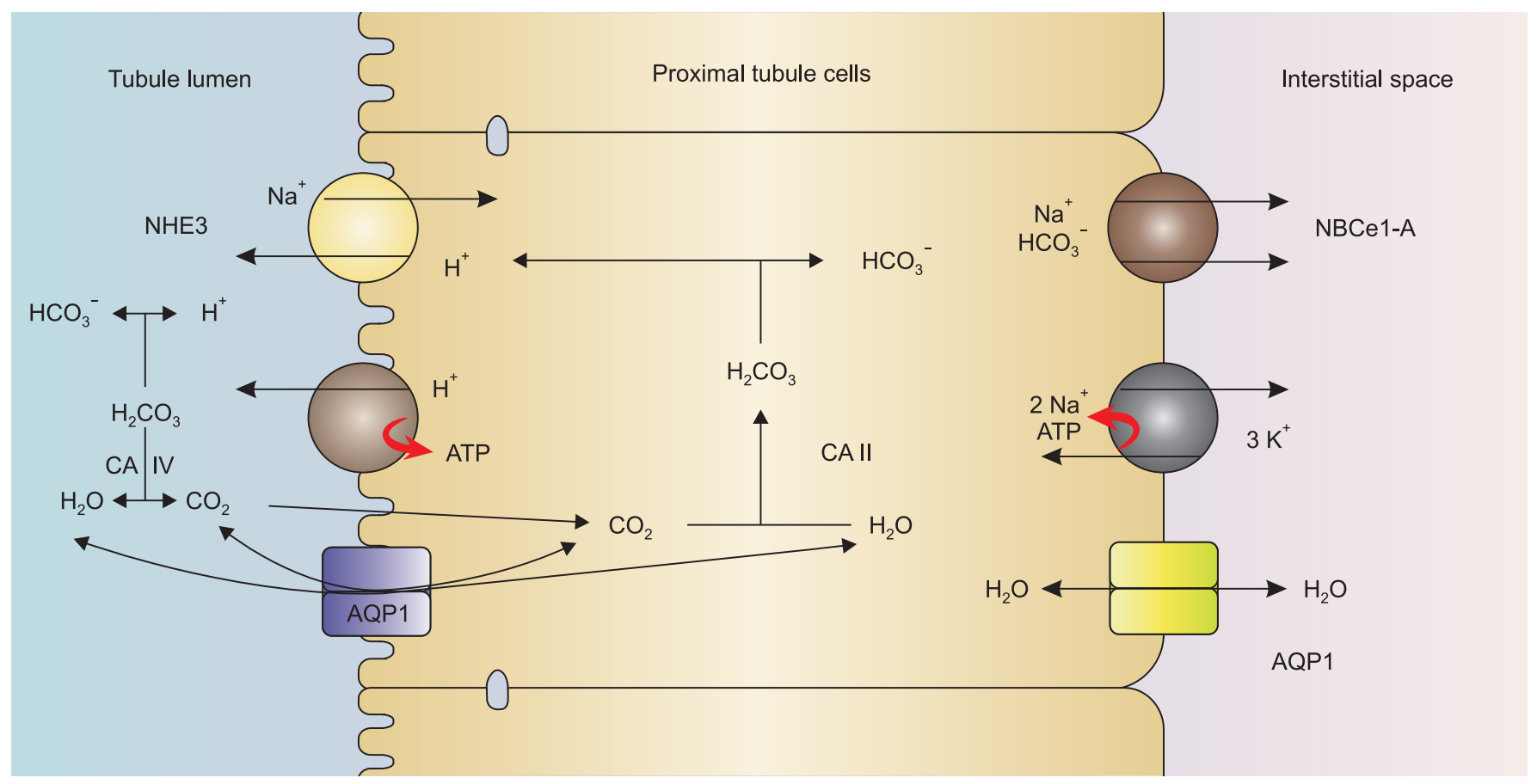

Figure 1. Bicarbonate reabsorption mechanisms in the proximal tubular cell. On the luminal side, the $\mathrm{Na}^{+}-\mathrm{H}^{+}$exchanger, $\mathrm{NHE3}$, carries out the majority ( $\sim 80 \%)$ of hydrogen ion secretion, while the proton pump $\mathrm{H}^{+}$-ATPase is responsible for $\sim 20 \%$ of proton transport. Note that $\mathrm{CO}_{2}$ entry via an $\mathrm{AQP} 1$ channel is controversial and not fully proven.

AQP1, aquaporin 1; CA, carbonic anhydrase; NBCe1-A, sodium bicarbonate cotransporter 1 variant A; $\mathrm{NHE}, \mathrm{Na}^{+} / \mathrm{H}^{+}$exchanger isoform 3. Modified from Singh et al [4] with permission. 
forms this function by preventing the luminal accumulation of $\mathrm{H}_{2} \mathrm{CO}_{3}$, creating a more favorable $\mathrm{pH}$ gradient for $\mathrm{H}^{+}$secretion (Fig. 1) $[4,5]$.

The luminal production of $\mathrm{CO}_{2}$ from the dehydration of $\mathrm{H}_{2} \mathrm{CO}_{3}$ is accelerated by glycosylphosphatidylinositol (GPI)-anchored CA IV enzyme [17]. The resulting water molecule $\left(\mathrm{H}_{2} \mathrm{O}\right)$ passes through the apical aquaporin channel. While it has long been assumed that $\mathrm{CO}_{2}$ diffuses freely across the cell membrane, recent evidence suggests a role for the apically expressed aquaporin 1 (AQP1) in the proximal tubule in facilitating the entry of $\mathrm{CO}_{2}$ to proximal tubular cells $[18,19]$. However, experiments by Fang et al [20] provide evidence against AQP1dependent $\mathrm{CO}_{2}$ permeability in the lung and kidney. More studies are needed to define the role of aquaporin channels in the entry of $\mathrm{CO}_{2}$ to cells.

Following the flux of $\mathrm{CO}_{2}$ into the proximal tubular cells, a reverse hydration reaction catalyzed by the cytoplasmic CA II yields $\mathrm{H}^{+}$and bicarbonate ions $[13,16,21]$. While the formed $\mathrm{H}^{+}$is recycled to the apical side, $\mathrm{HCO}_{3}{ }^{-}$is extruded with $\mathrm{Na}^{+}$across the basolateral cell membrane via the electrogenic sodium-bicarbonate cotransporter (NBCe1A [SLC4A4]) $[6,22,23]$. The driving force for this $\mathrm{HCO}_{3}{ }^{-}$ and $\mathrm{Na}^{+}$efflux is the basolateral membrane potential, which is generated by $\mathrm{Na}^{+} / \mathrm{K}^{+}$ATPase and the twin-pore domain acid-sensing $\mathrm{K}^{+} 2$ (TASK2) $\mathrm{K}^{+}$channels [23,24].

Bicarbonate escaping reabsorption by the proximal tubule $[25,26]$ is later reclaimed by the TAL via a similar process involving NHE3. Approximately $15 \%$ of the filtered bicarbonate load is reabsorbed by the TAL [27]. Apical NHE3 in the TAL functions similarly to its proxi-

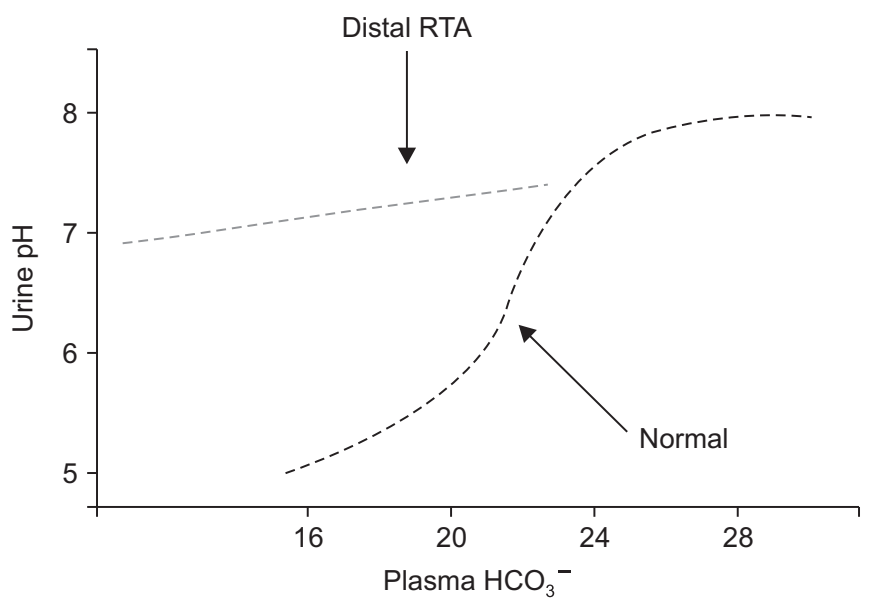

mal tubule counterpart and is the main contributor to $\mathrm{HCO}_{3}{ }^{-}$reabsorption in this segment of the nephron. A small but significant contribution of apical vacuolar $\mathrm{H}^{+}$ATPase also occurs here [27]. Once $\mathrm{HCO}_{3}^{-}$is regenerated intracellularly from $\mathrm{H}_{2} \mathrm{CO}_{3}$ (catalyzed by CA II and CA XV [6]), it exits through the basolateral membrane of the TAL cell mainly via the $\mathrm{Cl}^{-} / \mathrm{HCO}_{3}{ }^{-}$exchanger (AE2 anion exchanger) $[6,27]$ and the $\mathrm{K}^{+} / \mathrm{HCO}_{3}{ }^{-}$cotransporter [27] .

In the distal nephron and collecting tubules, acid secretion and thus bicarbonate reabsorption is achieved by the $\alpha$-intercalated cell, whereas bicarbonate secretion occurs in the $\beta$-intercalated cell [8]. In $\alpha$-intercalated cells, urinary acidification involves a combination of energy-dependent proton secretion across the apical surface mediated mainly by a hydrogen ATPase and, to a lesser extent, hydrogen potassium ATPase [8]. Basolateral chloridebicarbonate exchange serves to transport bicarbonate back into the blood via a band-3 protein, AE1, which is also critically important for continued acid excretion via the apical $\mathrm{H}^{+}$-ATPase and $\mathrm{H}^{+} / \mathrm{K}^{+}$-ATPase pumps [28-31].

\section{Isolated proximal RTA}

Impaired $\mathrm{HCO}_{3}{ }^{-}$reabsorption in proximal RTA can be understood as a decrease in the renal threshold for $\mathrm{HCO}_{3}{ }^{-}$reabsorption $[1,2,32]$. In this form of RTA, proximal $\mathrm{HCO}_{3}{ }^{-}$reabsorption can only accommodate a portion of the filtered $\mathrm{HCO}_{3}^{-}$. The portion "rejected" by the proximal tubule cannot be totally reclaimed distally and therefore appears in the urine in large amounts when plasma $\mathrm{HCO}_{3}{ }^{-}$is above a given threshold (usually 16-20

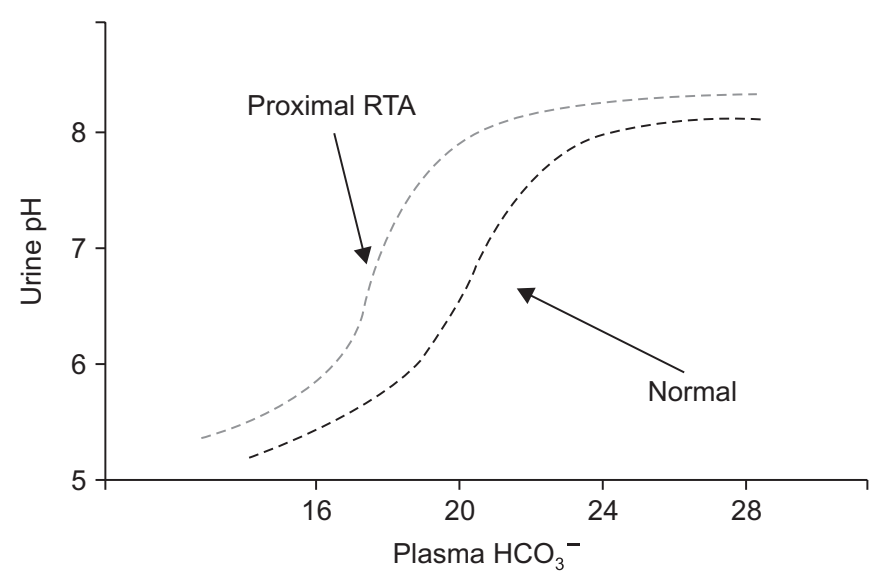

Figure 2. Differences in urinary $\mathrm{pH}$ and plasma bicarbonate in proximal and distal renal tubular acidosis (RTA).

Adapted from the article of Haque et al [2] with permission. 
$\mathrm{mEq} / \mathrm{L}$ ). If plasma $\mathrm{HCO}_{3}{ }^{-}$falls below this level, there is sufficient capacity for proximal tubular $\mathrm{HCO}_{3}^{-}$reabsorption such that urine $\mathrm{HCO}_{3}{ }^{-}$, and thus urine $\mathrm{pH}$, can fall to near normal levels (Fig. 2) [1,2,32]. Isolated proximal RTA can be hereditary or acquired as discussed below.

\section{Hereditary proximal RTA}

Isolated proximal RTA can be autosomal dominant, autosomal recessive, and sporadic. The autosomal recessive type is associated with severe growth retardation, ocular abnormalities such as glaucoma, cataracts and band keratopathy, and mental retardation $[23,33]$. This autosomal recessive type has been associated with mutations in the basolateral NBCel $[23,33]$. Mutations in this transporter lead to reduced activity and/or trafficking, disrupting the normal bicarbonate reabsorption process of the proximal tubules.

To our knowledge, autosomal dominant proximal RTA has been reported only in a single Costa Rican family $[2,34]$. The clinical features include mild growth retardation and reduced bone density. Sporadic isolated proximal RTA is a non-familial transient disorder that has been reported during infancy $[2,35]$. Patients with this disorder experience defective renal and intestinal bicarbonate reabsorption [33].

An isolated defect of proximal tubular $\mathrm{HCO}_{3}^{-}$reabsorption is also caused by the use of CA inhibitors. A deficiency or a malfunction in luminal CA IV could lead to impairment of proximal $\mathrm{HCO}_{3}{ }^{-}$reabsorption but, to our knowledge, CA IV deficiency has not been demonstrated

\section{Table 1. Inherited causes of Fanconi syndrome}

Primary Fanconi syndrome
$\mathrm{NaP}_{\mathrm{i}}-\mathrm{Il}$ cotransporter mutation
EHHADH gene mutation
HNF4A gene (R76W) mutation
Fanconi syndrome associated with inherited systemic diseases
Cystinosis
Galactosemia
Hereditary fructose intolerance
Tyrosinemia
Lowe syndrome
Alport syndrome
Wilson disease
Mitochondrial disorders
Lysinuric protein intolerance
Fanconi-Bickel syndrome

in patients with hereditary proximal RTA. By contrast, familial RTA has been long recognized in patients with inherited CA II deficiency in red blood cells [5,36-38]. These patients had features of both proximal and distal RTA (type III RTA) as well as osteopetrosis, cerebral calcification, and mental retardation.

Hereditary distal RTA with associated features of proximal tubular dysfunction (low-molecular-weight proteinuria, generalized hyperaminoaciduria, hypophosphatemia with hyperphospaturia, and hypouricemia with hyperuricosuria) was described in two siblings with ATP6V1B1 mutation [38]. This rare association is not fully understood, although it may go away after correction of the hypokalemia.

\section{Acquired proximal RTA}

CA inhibitors, such as acetazolamide are often used to manage conditions such as glaucoma (by reducing intraocular pressure), mountain sickness, or increased intracranial pressure [39] and are a well-recognized cause of isolated proximal RTA [9]. Three CA inhibitors (acetazolamide, methazolamide, and dichlorphenamide) can be administered systemically. The other two CA inhibitors (brinzolamide and dorzolamide) are applied topically. All CA inhibitors are sulfonamide derivatives with the potential to cause proximal RTA [39]. The defect in $\mathrm{HCO}_{3}{ }^{-}$reabsorption with CA inhibitors can be explained by inhibition of CA IV located in the apical membrane of the proximal tubule cells. Some CA inhibitors, such as acetazolamide and benzolamide, are less membranepermeable than others and as such are not as effective inhibitors of cytosolic CA as membrane-bound CA [40]. CA inhibitors typically cause pure proximal RTA as a result of inhibition of the membrane-bound CA IV isoform, resulting in the isolated inhibition of $\mathrm{HCO}_{3}{ }^{-}$reabsorption without any associated features of Fanconi syndrome [41].

\section{Fanconi syndrome}

The inherited causes of Fanconi syndrome can be primary or secondary to systemic diseases (Table 1). Most often, however, Fanconi syndrome is the consequence of drug-induced nephrotoxicity. 


\section{Primary Fanconi syndrome}

Primary Fanconi syndrome is usually caused by a missense mutation in the sodium phosphate cotransporter $\left(\mathrm{NaP}_{\mathrm{i}}-\mathrm{II}\right)$ in the proximal tubular apical membrane [42] A new form of inherited Fanconi syndrome recently described by Klootwijk et al [43] in an extended black family is caused by a mutation of the $E H H A D H$ gene, an enzyme involved in peroxisomal oxidation of fatty acids and expressed in the proximal tubule. This mutation leads to impaired oxidative phosphorylation and a reduction in ATP available in proximal tubular epithelial cells, which results in turn in defects in the transport of molecules across the proximal convoluted tubule (PCT) cells [43].

Another recently reported cause of Fanconi syndrome is a mutation in the HNF4A gene [44]. HNF4A encodes a member of the nuclear receptor superfamily of liganddependent transcription factors. Most of the information on this gene come from studies in hepatocytes, but its role in the kidney is not completely understood. The R76W mutation in HNF4A causes additional features not seen in Fanconi syndrome: nephrocalcinosis, renal impairment, hypercalciuria with relative hypocalcemia, hypermagnesemia, neonatal hyperinsulinism, and macrosomia [44].

\section{Fanconi syndrome associated with inherited systemic} disease

The secondary causes of Fanconi syndrome include inherited cystinosis, galactosemia, hereditary fructose intolerance, tyrosinemia, Lowe syndrome, Alport syndrome, Wilson disease, and mitochondrial disorders (Table 2). The most common inherited cause of Fanconi syndrome is cystinosis [45], a lysosomal storage disease characterized by the abnormal accumulation of the amino acid cystine $[46,47]$. It is transmitted as an autosomal recessive trait and has three forms: infantile (nephropathic), late-onset (juvenile), and adult (benign). Patients with the adult form do not develop urinary problems and only experience ocular manifestations such as photophobia [46].

Cystinosis is caused by mutations in the CTNS gene that encodes the lysosomal cystine transporter, cystinosin $[46,48]$. This leads to the accumulation of cystine within lysosomes and results in end-organ damage $[46,48]$. Re- nal proximal tubular cells are apparently highly susceptible to the effects of excessive accumulation of cystine, including damage to the renal proximal tubular cells and the ensuing Fanconi syndrome [35]. Various mechanisms are involved in the kidney damage observed in cytinosis including cysteinylation of protein kinase delta, which increases apoptosis of the cysteine-laden renal proximal convoluted tubule cells [49,50]; ATP depletion and inhibition of $\mathrm{Na}^{+}$dependent transporters secondary to cysteine accumulation [50,51]; and decreased expression of megalin, cubilin, and sodium transporters at the apical surface of proximal convoluted tubule cells [50].

Dent disease is not usually considered a cause of Fanconi syndrome but it shares some features of Fanconi syndrome, such as hypophosphatemia. Dent disease is an X-linked disorder with two subtypes. Dent disease 1 is caused by mutations in the CLCN5 gene, which encodes for an endosomal hydrogen chloride $\left(\mathrm{H}^{+} / \mathrm{Cl}^{-}\right)$exchange transporter. Dent disease 2 is caused by mutations in the OCRL gene, which encodes for a 5-phosphatase that is involved in cellular trafficking [52]. Both subtypes of Dent disease manifest in childhood in as varying degrees of proximal tubular dysfunction, including low-molecularweight proteinuria, hypercalciuria, nephrocalcinosis,

Table 2. Acquired causes of Fanconi syndrome

Associated with systemic diseases
Amyloidosis
Multiple myeloma/light chain disease
Paroxysmal nocturnal hemoglobinuria,
Renal transplantation
Tubulo-interstitial nephritis
Membranous nephropathy with anti-tubular antibodies
Drug-induced
Nucleotide reverse-transcriptase inhibitors: tenofovir, adefovir,
didanosine, lamivudine, stavudine
Anticancer drugs: ifosfamide, oxaliplatin, cisplatin
Anti-convulsant drugs: valproic acid, topiramate
Antibiotics: aminoglycosides, expired tetracyclines
DNA polymerase inhibitor: cidofovir
Others: deferasirox, streptozocin, lenalidomide, apremilast
Miscellaneous causes
Heavy metals (lead, cadmium, mercury, copper)
L-lysine and L-arginine
Aristolochic acid (Chinese herb nephropathy)
Fumaric acid
Suramin
Paraquat


nephrolithiasis, hypophosphatemia, and renal failure that eventually progresses to end-stage renal disease. Dent disease 2 tends to be less severe.

Mutations in the OCRL pathway can also lead to Lowe syndrome (also known as oculocerebrorenal syndrome), an X-linked disorder that affects the kidneys, eyes, and the brain. In Lowe syndrome, which is more severe than Dent disease 2 in terms of renal manifestations, bicarbonate wastage leads to the development of proximal RTA [53].

\section{Acquired causes of Fanconi syndrome}

Drug-induced nephrotoxicity is the most common acquired cause of Fanconi syndrome, followed by lightchain-associated Fanconi syndrome [54]. The acquired causes of Fanconi syndrome are summarized in Table 2.

\section{Fanconi syndrome associated with drug nephrotoxicity}

\section{Anti-retroviral medications}

Numerous antiretroviral medications have been implicated in Fanconi syndrome in human immunodeficiency virus (HIV)-positive patients [55,56]. Earle et al [56] described three cases in which HIV patients developed generalized tubular dysfunction with hypophosphatemia, metabolic acidosis, phosphaturia, glycosuria, and generalized aminoaciduria. Serum analysis revealed hypophosphatemia in all three, but serum bicarbonate was low-normal. Tenofovir, adefovir, and cidofovir are all nucleotide reverse-transcriptase inhibitors. Nonetheless, Fanconi syndrome has also been reported with nucleoside reverse-transcriptase inhibitors such as lamivudine, stavudine, and didanosine [57-59].

Three mechanisms of tenofovir nephrotoxicity have been suggested, including drug excretion in the proximal tubules, genetic association, and mitochondrial toxicity [60]. Proximal tubules are involved in the excretion of several drugs, including tenofovir, which enters proximal tubule cells through basolateral organic anion transporters and exits using apical transporter multidrugresistance-associated protein 4 [61]. Didanosine uses the same organic anion transporters to enter the proximal tubular cells. When combined with tenofovir, both drugs compete for the same transporters, leading to increased renal toxicity [60].
Renal dysfunctions (including Fanconi syndrome) due to tenofovir are usually reversible with cessation of the drug, although persistent Fanconi syndrome has been reported. Data regarding tenofovir dose reduction as a strategy to ameliorate nephrotoxicity and aid in the recovery of renal function are lacking. Because of severe nephrotoxicity, tenofovir disoproxil fumarate (TDF) has been almost completely replaced by tenofovir alafenamide (TAF) for treatment of HIV infection and chronic hepatitis B virus infection in the United States. One of the reasons for this change is the fact that TAF is less nephrotoxic than TDF $[62,63]$. However, a case of Fanconi syndrome in a patient treated with TAF has been recently reported [63].

Several reports have been published in which didanosine is associated with the development of Fanconi syndrome in HIV-positive patients [58,59,64]. Izzedine et al [59] reported a case of Fanconi syndrome and diabetes insipidus in an HIV patient treated with didanosine among other medications. The patient was hospitalized for fatigue, dehydration with weight loss, and polyuria. Laboratory examination on admission revealed normal anion-gap metabolic acidosis hypokalemia, hypophosphatemia, and hypouricemia. A 24 hours urine collection on the second hospital day revealed a urine output of $4.5 \mathrm{~L}$, heavy glycosuria in spite of normal serum glucose, aminoaciduria, and $3.5 \mathrm{~g}$ of mixed proteinuria [59]. After didanosine cessation, and despite the continuation of adefovir, the plasma levels of bicarbonate potassium and uric acid normalized. Urinalysis was negative for glycosuria, with a progressive reduction in proteinuria [59].

D'Ythurbide et al [64] also reported Fanconi syndrome and diabetes insipidus in an HIV patient being treated with didanosine, lamivudine, atazanavir, and ritonavir. On admission, the patient had hypophosphatemia, hypouricemia, hyperchloremic metabolic acidosis with a normal anion gap, normoglycemic glycosuria, low-molecular-weight proteinuria, and high fractional excretion of phosphate [64]. The patient recovered completely one month after discontinuation of didanosine, while treatment with the other medications was continued [64].

\section{Ifosfamide}

Ifosfamide is an alkylating agent used to treat different types of cancers in adult and pediatric populations $[65,66]$. A synthetic analog of cyclophosphamide, its use 
is sometimes limited by its adverse urological and renal toxicities, such as hemorrhagic cystitis and Fanconi syndrome. While both ifosfamide and cyclophosphamide can cause hemorrhagic cystitis, only ifosfamide is associated with Fanconi syndrome. The introduction of the uroprotective thiol compound "Mesna" (sodium 2-mercaptoethanesulfonate) has virtually eliminated urotoxicity associated with both cyclophosphamide and ifosfamide and allowed the use of higher and more frequent dosing. However, mesna has shown no preventive effect on the tubular toxicity of ifosfamide, which manifests in Fanconi syndrome $[67,68]$. This is likely due to insufficient delivery of mesna to the renal tubule, leading to failure to provide adequate protection of tubular glutathione from depletion by the metabolite(s) [69].

The incidence of Fanconi syndrome in treated patients is reportedly between $1.4 \%$ and $5 \%$ [67]. The toxicity of ifosfamide and the late onset of the syndrome following discontinuation have been recognized in several studies [67,70-72].

Most information on ifosfamide nephrotoxicity comes from studies in children as its use in pediatric oncology is common [70-72]. By contrast, reports of ifosfamiderelated Fanconi syndrome in adult patients are scarce $[73,74]$. In a long-term assessment of ifosfamide-related renal toxicity in adult patients, Farry et al [75] reported a steady decline in the estimated GFR, although none of the patients progressed to end-stage renal disease.

Several studies have improved our understanding of the mechanism of renal injury due to ifosfamide. Studies in rats by Nissim et al [76] showed that chloroacetaldehyde (CAA), the active metabolite of ifosfamide, causes renal injury by inhibiting nicotinamide adenine dinucleotide (reduced) (NADH):ubiquinone oxidoreductase (Complex-1; C-I), one of the enzymes in the oxidative phosphorylation pathway. The authors demonstrated that CAA accumulates in the kidney cortex following ifosfamide treatment. Inhibition of C-I led to increased NADH and decreased NAD. Moreover, the administration of agmatine (AGM), a metabolite of arginine decarboxylation, with ifosfamide prevented these changes and raised cyclic adenosine monophosphate levels. AGM, therefore, has been suggested as a potential compound for the prevention of ifosfamide-induced tubular dysfunctions, including Fanconi syndrome [76]. Yaseen et al [77] discovered that CAA inhibits endocytosis in the rat proximal tubules. This inhibition was attributed to a decrease in ATP levels and inhibition of Vacuolar-type $\mathrm{H}^{+}$ATPase induced by CAA.

\section{Oxaliplatin and cisplatin}

Oxaliplatin has been reported to cause both isolated proximal RTA as well as proximal RTA with Fanconi syndrome $[78,79]$. It was first reported in a patient being treated with oxaliplatin for colon adenocarcinoma. The patient developed hypokalemic, hyperchloremic metabolic acidosis with a normal anion gap [78]. The presence of glycosuria and low serum phosphate levels prompted the diagnosis of Fanconi syndrome [78]. In another report of oxaliplatin treatment for adenocarcinoma of the colon, the patient developed $\mathrm{HCO}_{3}{ }^{-}$wasting and severe hypokalemic, hyperchloremic metabolic acidosis with a normal anion gap but no other abnormalities, suggesting isolated proximal RTA [79].

Fanconi syndrome has also been described with cisplatin [80]. Cisplatin administration in mice caused a significant increase in the urinary concentrations of glucose, amino acids, and trichloroacetic acid cycle metabolites, such as pyruvate and lactate, within 48 hours of administration [81]. Aminoaciduria in cisplatin-treated mice also preceded the elevation of serum creatinine. Cisplatin inhibits peroxisome proliferator-activated receptor-alpha activity and consequently fatty acid oxidation resulting in proximal tubular cell death $[81,82]$. Fibrates such as bezafibrate prevent this inhibition and may be protective against cisplatin-induced proximal tubule cell death [82]. It has also been suggested that one of the possible mechanisms of cisplatin-induced proximal tubule nephrotoxicity is reduced expression and function of sodiumdependent glucose transporters [81].

\section{Anticonvulsant therapies}

Several studies have reported the development of metabolic acidosis following treatment with topiramate [83-85]. Topiramate is an anti-epileptic drug used for seizure disorders and migraine prophylaxis [83]. Sacré et al [86] reported a case in which topiramate was used for migraine prophylaxis in a patient who developed hyperchloremic metabolic acidosis with a normal GFR and positive urine anion gap (UAG). The authors reported that the patient had both proximal and distal RTA. It has been suggested that inhibition of CA II by topiramate can 
cause development of mixed RTA $[39,87]$. Winum et al [39] found that topiramate is a potent inhibitor of human CA II and XII and a medium potency inhibitor of CA IV. However, Maryanoff et al [88] found that topiramate has low activity against CA II. X-ray crystallography studies have revealed a close association between bound topiramate and the active site of CA II, a finding that is congruent with topiramate's potent inhibitory activity against CA II [87]. The inhibition of cytosolic CA II by topiramate provides a reasonable explanation for the development of mixed RTA.

Another anticonvulsant that can rarely be a cause of Fanconi syndrome is valproic acid. A few case reports of Fanconi syndrome with the use of valproic acid have been published [89-91]. Several reports describe normalization of laboratory values after cessation of valproate $[90,91]$. The mechanism for this reaction is not clear, but a direct toxic effect of valproic acid on mitochondria in the proximal tubules has been suggested $[92,93]$.

\section{Miscellaneous}

Maleic acid

In a model of Fanconi syndrome produced by administering maleic acid to rats and dogs, renal cortical $\mathrm{Na}^{+} /$ $\mathrm{K}^{+}$-ATPase activity is markedly diminished [94]. The relevance of these observations to human Fanconi syndrome remains to be determined but the generalized proximal tubular dysfunction in Fanconi syndrome could be a result of a generalized defect of $\mathrm{Na}^{+}$-coupled apical membrane transporters, a defect in basolateral $\mathrm{Na}^{+} / \mathrm{K}^{+}$ATPase, or metabolic disorders that lower intracellular concentrations of ATP [3].

\section{Deferasirox}

Diseases such as beta thalassemia, sickle cell disease, and myelodysplastic syndromes require long-term blood transfusions as the mainstay of treatment. Iron-chelating agents have been developed to counteract accumulation of dangerous levels of iron. The main agent, deferoxamine, requires administration as a slow, continuous subcutaneous or intravenous infusion five to seven times per week [95], which may lead to non-compliance. Deferasirox, which is administered orally using a once-a-day dosing schedule, is far more likely to ensure compliance and is therefore increasingly being prescribed by hema- tologists. However, nephrotoxicity is the most serious and frequent adverse effect of deferasirox treatment and can present as an acute or chronic decrease in GFR. Features of proximal tubular dysfunction may also be present [96]

Several recent case reports [97-99] and one study [100] have linked deferasirox to the development of Fanconi syndrome in patients undergoing iron-chelation therapy. In one retrospective study by Chuang et al [100], five of 57 patients with thalassemia treated with deferasirox developed Fanconi syndrome. The authors hypothesized that deferasirox is more toxic to the less-mature renal tubules in younger children when compared with the effect on the study's adult patients, who were relatively resistant to Fanconi syndrome [100]. Renal tubular dysfunction was not related to the dose of deferasirox and dose reduction did not ameliorate tubular dysfunction. Several mechanisms have been proposed, including deferasirox accumulation in the kidney, modulation of hemodynamics by excessively rapid iron removal, and iron-dependent cell death, but an exact mechanism has yet to be elucidated [96].

Aminoglycosides

The presence of glycosuria and aminoaciduria after exposure to gentamicin has been reported in rats [101]. Several cases of patients with aminoglycoside-induced Fanconi syndrome have been reported [102-105]. Ghiculescu and Kubler [102] reported the development of Fanconi syndrome in a 53-year-old man treated for respiratory infections with gentamicin. The patient developed hypophosphatemia, hypocalcemia, hyperphosphaturia, and aminoaciduria. These electrolyte disturbances persisted until gentamicin therapy was stopped, recurred with a re-challenge, and did not correct with calcium and phosphate supplementation [102].

In most reported cases, the alteration in reabsorption predominately affected neutral amino acids and, to a lesser extent, acidic amino acids [102].

In the case of gentamicin, recent in vitro and in vivo studies performed in LLCPK1 cells, as well as in mouse kidney tissue, have shown that aminoglycoside antibiotics reduce glucose reabsorption in kidney tissue by reducing mRNA, protein expression, and function of sodium-dependent glucose transporters in the apical membrane of the proximal tubule [106]. 
L-cationic amino acids

L-cationic amino acids, such as L-lysine and L-arginine, have a profound inhibitory effect on proximal $\mathrm{HCO}_{3}^{-}$reabsorption and can potentially cause proximal RTA [107].

Ingestion of L-lysine has been reported as a cause of Fanconi syndrome [108]. Several cases of Fanconi syndrome have been reported involving patients with lysinuric protein intolerance (LPI) $[109,110]$, a rare autosomal recessive multiorgan disorder in which the renal and intestinal transport of the cationic amino acids lysine, arginine, and ornithine is defective [111]. This leads to heavy L-lysine loads on renal tubules. Most, but not all, of the symptoms of LPI have been linked to a secondary ureacycle derangement due to impaired transport of cationic amino acids. Typically, symptoms begin after weaning, with refusal of feeding, vomiting and consequent failure to thrive $[112,113]$. Two major complications, pulmonary alveolar proteinosis and renal disease, are increasingly observed in LPI patients [113,114]. Interestingly, the authors did not consider the intratubular accumulation of lysine as a cause for the patient with Fanconi syndrome [109]. This is supported by the fact that, hyperlysinemia, an autosomal recessive disease characterized by increased lysine levels in the blood due to a mutation in the enzyme $\alpha$-aminoadipic semialdehyde synthase, is relatively benign and does not lead to Fanconi syndrome [115]. Instead, the authors suggest that the cause of the proximal tubular dysfunction in LPI is either due to diminished resorptive area and decreased availability of transport proteins, or increased back-leak of solutes from the proximal tubular cell [110].

\section{Apremilast}

Apremilast is a phosphodiesterase 4 inhibitor used in the treatment of psoriasis and psoriatic arthritis. In a report describing a case of Fanconi syndrome in a patient treated with apremilast [116], the patient developed hypokalemia, hyperchloremic metabolic acidosis, low uric acid concentration, a positive urinary anion gap, and proteinuria two weeks after the initiation of apremilast therapy [116]. These abnormalities resolved upon discontinuation of the drug. Two months after the initial event, the patient resumed apremilast therapy, but developed similar abnormalities after 17 days. Apremilast was again discontinued and the patient recovered after [116].

\section{Heavy metals}

Heavy metals such as lead, cadmium, and mercury are reportedly associated with proximal RTA $[117,118]$ and chronic cadmium exposure has been reported to cause Fanconi syndrome $[119,120]$. Cadmium accumulates in the proximal tubular cells through receptor-mediated endocytosis of metallothionein-bound Cd (Cd-MT). $\mathrm{Cd}-\mathrm{MT}$ complexes are degraded in endosomes and lysosomes that release free $\mathrm{Cd}^{2+}$ into the cytosol, where it generates reactive oxygen species, triggering a cascade of damaging cellular events that can cause generalized proximal tubular dysfunction [119].

\section{Fanconi syndrome associated with systemic disease}

The acquired causes of Fanconi syndromes are usually associated with features of proximal RTA and include amyloidosis, multiple myeloma, paroxysmal nocturnal hemoglobinuria, renal transplantation (Table 2) [54,121124]. A discussion of these individual entities is beyond the scope of this review.

\section{Clinical diagnosis}

The hallmark of Fanconi syndrome is increased excretion of substances usually reabsorbed in the PCT while their levels in the plasma are not elevated. The presence of proximal RTA usually raises the suspicion of Fanconi syndrome in patients receiving one of the causative agents.

Fanconi syndrome is usually suspected when a patient develops tubulopathy in association with one of the causes discussed previously. There is often a temporal relationship between the cause and the development of Fanconi syndrome, although exceptions exist in which the syndrome develops months or years after the introduction of the causative agent (such as tenofovir [125]). Other causes, such as apremilast, can result in metabolic derangements within a few weeks of starting treatment.

A diagnosis of proximal RTA requires establishing the presence of urinary $\mathrm{HCO}_{3}{ }^{-}$wastage. This is demonstrated with a high urine $\mathrm{pH}$ in the presence of normal or slightly reduced plasma $\mathrm{HCO}_{3}{ }^{-}$. Traditionally, a fractional $\mathrm{HCO}_{3}{ }^{-}$ excretion of $\geq 15 \%$ when the plasma $\mathrm{HCO}_{3}{ }^{-}$is normal is said to be needed to establish the diagnosis of proximal RTA [2]. However, in the proper context, a fractional excretion of only $5 \%$ is consistent with proximal RTA be- 
cause the distal and collecting tubules can reclaim some of the $\mathrm{HCO}_{3}^{-}$"rejected" by the proximal tubule. When the fractional excretion is $15 \%$ or higher, the defect in the proximal tubule for $\mathrm{HCO}_{3}^{-}$reabsorption must be quite severe.

As previously mentioned, patients with proximal RTA can lower urine $\mathrm{pH}$ to $<5.5$ when the plasma $\mathrm{HCO}_{3}{ }^{-}$is lower than the renal threshold for $\mathrm{HCO}_{3}^{-}$reabsorption. This is in contrast to patients with classic or type I RTA who cannot lower urine $\mathrm{pH}$ maximally regardless of the degree of the acidosis (Fig. 2).

Another bedside diagnostic tool is the use of the urinary anion gap (UAG) as a surrogate marker of ammonium excretion. The UAG is consistently increased (positive) in distal RTA [126-128]. By contrast, in proximal RTA and in the presence of metabolic acidosis, one would expect the UAG to be appropriately decreased (negative). However, there are limited data on the UAG in proximal RTA, and some patients with proximal RTA may not have a maximal ammonium excretion during acidosis. Accordingly, the UAG may not be appropriately reduced (negative). Data on urine ammonium and UAG in proximal RTA are clearly needed.

Urine studies, which are underutilized in clinical practice, are necessary for the diagnosis of Fanconi syndrome. There is usually increased fractional excretion of phosphate and uric acid as well as euglycemic glycosuria. Increased urinary excretion of amino acid and lowmolecular-weight proteins are sensitive markers of proximal tubulopathy and often used to confirm the diagnosis of Fanconi syndrome. Urinary retinol-binding protein 4 in urine appears to be the most sensitive biomarker for proximal tubulopathy but it is not readily available as a diagnostic tool in most places [129]. The diagnosis is often confirmed by the improvement of tubulopathy following the discontinuation of the offending agent(s).

\section{Treatment}

The autosomal dominant and recessive forms of proximal RTA are usually permanent and require life-long alkali therapy. In contrast, sporadic isolated proximal RTA is transient and alkali therapy can be discontinued after several years. After discontinuation of the alkali therapy, the condition does not return. This defect has been ascribed to proximal tubular immaturity in some infants
[32].

The goal of treatment in Fanconi syndrome is to stop the causative agent (when possible) and to replenish the solutes that are wasted in the urine due to the lack of proximal tubular reabsorption. Loss of glucose, uric acid and amino acids is usually asymptomatic. Loss of phosphate, however, can lead to rickets in children and osteomalacia in adults. Hypophosphatemia in Fanconi syndrome and proximal RTA can be exacerbated by vitamin D deficiency, and both phosphate and vitamin D levels should be checked and supplements administered [130].

All patients with proximal RTA should receive $\mathrm{HCO}_{3}{ }^{-}$ supplementation. Alkali therapy is of particular importance in children to prevent growth retardation due to acidosis. Large amounts of $\mathrm{HCO}_{3}^{-}$are usually necessary given the magnitude of $\mathrm{HCO}_{3}{ }^{-}$wastage in proximal RTA and sometimes Fanconi syndrome. An amount of 5 to 15 $\mathrm{mEq} / \mathrm{kg}$ is usually recommended [3]. Thiazide diuretics enhance $\mathrm{HCO}_{3}^{-}$reabsorption in the PCT and the loop of Henle by reducing extracellular volume and are used to minimize the required amount of $\mathrm{HCO}_{3}^{-}$. Potassium levels should be monitored and supplemented when necessary, given that both $\mathrm{HCO}_{3}{ }^{-}$supplementation and thiazide diuresis lead to hypokalemia by enhancing $\mathrm{K}^{+}$ excretion in the collecting duct [3].

Any time a medication is suspected to be the cause of Fanconi syndrome in a patient, it should be stopped if possible and efforts should be made to find an alternative. When a suitable replacement is not present, lowering the dose should be performed, although, as mentioned previously, some cases of Fanconi syndrome are not dose-related.

\section{Conflicts of interest}

All authors have no conflicts of interest to declare.

\section{Authors' contributions}

Daniel Batlle and Ibrahim Kashoor participated in the data collection and wrote the manuscript. Daniel Batlle and Ibrahim Kashoor participated in the study design. Daniel Batlle and Ibrahim Kashoor participated in the conception, analysis, and interpretation of data. Daniel Batlle and Ibrahim Kashoor provided intellectual content 
of critical importance to the work and technical support. Daniel Batlle and Ibrahim Kashoor participated in the study design and coordination and helped to draft the manuscript. All authors read and approved the final manuscript.

\section{References}

[1] Rodriguez Soriano J, Boichis H, Stark H, Edelmann CM Jr. Proximal renal tubular acidosis. A defect in bicarbonate reabsorption with normal urinary acidification. Pediatr Res 1967;1:81-98.

[2] Haque SK, Ariceta G, Batlle D. Proximal renal tubular acidosis: a not so rare disorder of multiple etiologies. Nephrol Dial Transplant 2012;27:4273-4287.

[3] Moorthi K, Batlle D. Renal tubular acidosis. In: Gennari J, Adrogue HJ, Galla JH, Madias NE, eds. Acid-base disorders and their treatment. Boca Raton: Taylor and Francis; 2005. p. 417-459.

[4] Singh AS, Batlle D, Moran-Farias J, Valles P. Inherited proximal and distal renal tubular acidosis. In: Scientific american nephrology, dialysis and transplantation. Toronto: Decker; 2017.

[5] Batlle D, Haque SK. Genetic causes and mechanisms of distal renal tubular acidosis. Nephrol Dial Transplant 2012;27:3691-3704.

[6] Kurtz I. Renal tubular acidosis: $\mathrm{H}+$ /base and ammonia transport abnormalities and clinical syndromes. $A d v$ Chronic Kidney Dis 2018;25:334-350.

[7] Alper SL. Familial renal tubular acidosis. J Nephrol 2010; 23 Suppl 16:S57-S76.

[8] Vallés PG, Batlle D. Hypokalemic distal renal tubular acidosis. Adv Chronic Kidney Dis 2018;25:303-320.

[9] Izzedine H, Launay-Vacher V, Isnard-Bagnis C, Deray G. Drug-induced Fanconi's syndrome. Am J Kidney Dis 2003; 41:292-309.

[10] Klootwijk ED, Reichold M, Unwin RJ, Kleta R, Warth R, Bockenhauer D. Renal Fanconi syndrome: taking a proximal look at the nephron. Nephrol Dial Transplant 2015; 30:1456-1460.

[11] Foreman JW. Fanconi syndrome. Pediatr Clin North Am 2019;66:159-167.

[12] Sirac C, Bridoux F, Essig M, Devuyst O, Touchard G, Cogné M. Toward understanding renal Fanconi syndrome: step by step advances through experimental models. Contrib Nephrol 2011;169:247-261.
[13] Boron WF. Acid-base transport by the renal proximal tubule. JAm Soc Nephrol 2006;17:2368-82.

[14] Sarker R, Cha B, Kovbasnjuk O, et al. Phosphorylation of NHE3-S719 regulates NHE3 activity through the formation of multiple signaling complexes. Mol Biol Cell 2017;28: 1754-1767.

[15] Cotter K, Stransky L, McGuire C, Forgac M. Recent insights into the structure, regulation, and function of the VATPases. Trends Biochem Sci 2015;40:611-622.

[16] Purkerson JM, Schwartz GJ. The role of carbonic anhydrases in renal physiology. Kidney Int 2007;71:103-115.

[17] Zhu XL, Sly WS. Carbonic anhydrase IV from human lung. Purification, characterization, and comparison with membrane carbonic anhydrase from human kidney. J Biol Chem 1990;265:8795-8801.

[18] Eladari D, Kumai Y. Renal acid-base regulation: new insights from animal models. Pflugers Arch 2015;467:16231641.

[19] Boron WF. Sharpey-Schafer lecture: gas channels. Exp Physiol 2010;95:1107-1130.

[20] Fang X, Yang B, Matthay MA, Verkman AS. Evidence against aquaporin-1-dependent $\mathrm{CO} 2$ permeability in lung and kidney. J Physiol 2002;542(Pt 1):63-69.

[21] Hurst TK, Wang D, Thompson RB, Fierke CA. Carbonic anhydrase II-based metal ion sensing: advances and new perspectives. Biochim Biophys Acta 2010;1804:393-403.

[22] Huynh KW, Jiang J, Abuladze N, et al. CryoEM structure of the human SLC4A4 sodium-coupled acid-base transporter NBCe1. Nat Commun 2018;9:900.

[23] Kurtz I, Zhu Q. Proximal renal tubular acidosis mediated by mutations in NBCe1-A: unraveling the transporter's structure-functional properties. Front Physiol 2013;4:350.

[24] Warth R, Barrière $H$, Meneton $P$, et al. Proximal renal tubular acidosis in TASK2 $\mathrm{K}+$ channel-deficient mice reveals a mechanism for stabilizing bicarbonate transport. Proc Natl Acad Sci U S A 2004;101:8215-8220.

[25] Hamm LL, Simon EE. Roles and mechanisms of urinary buffer excretion. Am J Physiol 1987;253(4 Pt 2):F595-F605.

[26] Alexander RT, Bitzan M. Renal tubular acidosis. Pediatr Clin North Am 2019;66:135-157.

[27] Mount DB. Thick ascending limb of the loop of Henle. Clin J Am Soc Nephrol 2014;9:1974-1986.

[28] Alper SL, Darman RB, Chernova MN, Dahl NK. The AE gene family of $\mathrm{Cl} / \mathrm{HCO} 3-$ exchangers. J Nephrol 2002;15 Suppl 5:S41-S53.

[29] Wagner S, Vogel R, Lietzke R, Koob R, Drenckhahn D. Im- 
munochemical characterization of a band 3-like anion exchanger in collecting duct of human kidney. Am J Physiol 1987;253(2 Pt 2):F213-F221.

[30] Schuster VL. Function and regulation of collecting duct intercalated cells. Annu Rev Physiol 1993;55:267-288.

[31] Alper SL, Natale J, Gluck S, Lodish HF, Brown D. Subtypes of intercalated cells in rat kidney collecting duct defined by antibodies against erythroid band 3 and renal vacuolar H+-ATPase. Proc Natl Acad Sci U S A 1989;86:5429-5433.

[32] Rodríguez Soriano J. Renal tubular acidosis: the clinical entity. J Am Soc Nephrol 2002;13:2160-2170.

[33] Igarashi T, Sekine T, Inatomi J, Seki G. Unraveling the molecular pathogenesis of isolated proximal renal tubular acidosis. J Am Soc Nephrol 2002;13:2171-2177.

[34] Lemann J Jr, Adams ND, Wilz DR, Brenes LG. Acid and mineral balances and bone in familial proximal renal tubular acidosis. Kidney Int 2000;58:1267-1277.

[35] Finer G, Landau D. Clinical approach to proximal renal tubular acidosis in children. Adv Chronic Kidney Dis 2018; 25:351-357.

[36] Bolt RJ, Wennink JM, Verbeke JI, Shah GN, Sly WS, Bökenkamp A. Carbonic anhydrase type II deficiency. Am J Kidney Dis 2005;46:A50, e71-e3.

[37] Fathallah DM, Bejaoui M, Lepaslier D, Chater K, Sly WS, Dellagi K. Carbonic anhydrase II (CA II) deficiency in Maghrebian patients: evidence for founder effect and genomic recombination at the CA II locus. Hum Genet 1997; 99:634-637.

[38] Shah GN, Bonapace G, Hu PY, Strisciuglio P, Sly WS. Carbonic anhydrase II deficiency syndrome (osteopetrosis with renal tubular acidosis and brain calcification): novel mutations in CA2 identified by direct sequencing expand the opportunity for genotype-phenotype correlation. Hum Mutat 2004;24:272.

[39] Winum JY, Poulsen SA, Supuran CT. Therapeutic applications of glycosidic carbonic anhydrase inhibitors. Med Res Rev 2009;29:419-455.

[40] Supuran CT, Scozzafava A. Benzolamide is not a membrane-impermeant carbonic anhydrase inhibitor. J Enzyme Inhib Med Chem 2004;19:269-273.

[41] Keilani T, Segal R, Esparaz D, et al. Effect of dorzolamide, a novel topical carbonic anhydrase inhibitor, on urinary acidification in subjects with moderate renal impairment (abstract). J Investig Med 1995;43 Suppl 2:203A-415A.

[42] Magen D, Berger L, Coady MJ, et al. A loss-of-function mutation in NaPi-IIa and renal Fanconi's syndrome. $N$
Engl J Med 2010;362:1102-1109.

[43] Klootwijk ED, Reichold M, Helip-Wooley A, et al. Mistargeting of peroxisomal EHHADH and inherited renal Fanconi's syndrome. N Engl J Med 2014;370:129-138.

[44] Hamilton AJ, Bingham C, McDonald TJ, et al. The HNF4A R76W mutation causes atypical dominant Fanconi syndrome in addition to a $\beta$ cell phenotype. J Med Genet 2014;51:165-169.

[45] Baum M. The Fanconi syndrome of cystinosis: insights into the pathophysiology. Pediatr Nephrol 1998;12:492497.

[46] Wilmer MJ, Schoeber JP, van den Heuvel LP, Levtchenko EN. Cystinosis: practical tools for diagnosis and treatment. Pediatr Nephrol 2011;26:205-215.

[47] Langman CB, Barshop BA, Deschênes G, et al; Conference Participants. Controversies and research agenda in nephropathic cystinosis: conclusions from a "Kidney Disease: Improving Global Outcomes" (KDIGO) Controversies Conference. Kidney Int 2016;89:1192-1203.

[48] Bäumner S, Weber LT. Nephropathic cystinosis: symptoms, treatment, and perspectives of a systemic disease. Front Pediatr 2018;6:58.

[49] Park MA, Pejovic V, Kerisit KG, Junius S, Thoene JG. Increased apoptosis in cystinotic fibroblasts and renal proximal tubule epithelial cells results from cysteinylation of protein kinase Cdelta. J Am Soc Nephrol 2006;17:31673175.

[50] Cherqui S, Courtoy PJ. The renal Fanconi syndrome in cystinosis: pathogenic insights and therapeutic perspectives. Nat Rev Nephrol 2017;13:115-131.

[51] Kumar A, Bachhawat AK. A futile cycle, formed between two ATP-dependant gamma-glutamyl cycle enzymes, gamma-glutamyl cysteine synthetase and 5-oxoprolinase: the cause of cellular ATP depletion in nephrotic cystinosis? J Biosci 2010;35:21-25.

[52] De Matteis MA, Staiano L, Emma F, Devuyst O. The 5-phosphatase OCRL in Lowe syndrome and Dent disease 2. Nat Rev Nephrol 2017;13:455-470.

[53] Loi M. Lowe syndrome. Orphanet J Rare Dis 2006;1:16.

[54] Messiaen T, Deret S, Mougenot B, et al. Adult Fanconi syndrome secondary to light chain gammopathy. Clinicopathologic heterogeneity and unusual features in 11 patients. Medicine (Baltimore) 2000;79:135-154.

[55] Verhelst D, Monge M, Meynard JL, et al. Fanconi syndrome and renal failure induced by tenofovir: a first case report. Am J Kidney Dis 2002;40:1331-1333. 
[56] Earle KE, Seneviratne T, Shaker J, Shoback D. Fanconi's syndrome in HIV+ adults: report of three cases and literature review. J Bone Miner Res 2004;19:714-721.

[57] Nelson M, Azwa A, Sokwala A, Harania RS, Stebbing J. Fanconi syndrome and lactic acidosis associated with stavudine and lamivudine therapy. AIDS 2008;22:13741376.

[58] Crowther MA, Callaghan W, Hodsman AB, Mackie ID. Dideoxyinosine-associated nephrotoxicity. AIDS 1993;7: 131-132.

[59] Izzedine H, Launay-Vacher V, Deray G. Fanconi syndrome associated with didanosine therapy. AIDS 2005;19:844845.

[60] Hall AM, Hendry BM, Nitsch D, Connolly JO. Tenofovirassociated kidney toxicity in HIV-infected patients: a review of the evidence. Am J Kidney Dis 2011;57:773-780.

[61] Imaoka T, Kusuhara H, Adachi M, Schuetz JD, Takeuchi $\mathrm{K}$, Sugiyama Y. Functional involvement of multidrug resistance-associated protein 4 (MRP4/ABCC4) in the renal elimination of the antiviral drugs adefovir and tenofovir. Mol Pharmacol 2007;71:619-627.

[62] Sax PE, Wohl D, Yin MT, et al; GS-US-292-0104/0111 Study Team. Tenofovir alafenamide versus tenofovir disoproxil fumarate, coformulated with elvitegravir, cobicistat, and emtricitabine, for initial treatment of HIV-1 infection: two randomised, double-blind, phase 3 , non-inferiority trials. Lancet 2015;385:2606-2615.

[63] Bahr NC, Yarlagadda SG. Fanconi syndrome and tenofovir alafenamide: a case report. Ann Intern Med 2019 Jan 29 [Epub]. DOI: 10.7326/L18-0592.

[64] D’Ythurbide G, Goujard C, Méchaï F, Blanc A, Charpentier B, Snanoudj R. Fanconi syndrome and nephrogenic diabetes insipidus associated with didanosine therapy in HIV infection: a case report and literature review. Nephrol Dial Transplant 2007;22:3656-3659.

[65] Voûte PA, van den Berg H, Behrendt H, Michiels E, de Kraker J. Ifosfamide in the treatment of pediatric malignancies. Semin Oncol 1996;23(3 Suppl 7):8-11.

[66] Bokemeyer C, Harstrick A, Beyer J, et al. The use of doseintensified chemotherapy in the treatment of metastatic nonseminomatous testicular germ cell tumors. German Testicular Cancer Study Group. Semin Oncol 1998;25(2 Suppl 4):24-32.

[67] Rossi R, Pleyer J, Schäfers P, et al. Development of ifosfamide-induced nephrotoxicity: prospective follow-up in 75 patients. Med Pediatr Oncol 1999;32:177-182.
[68] Yaseen Z, Michoudet C, Baverel G, Dubourg L. In vivo mesna and amifostine do not prevent chloroacetaldehyde nephrotoxicity in vitro. Pediatr Nephrol 2008;23:611-618.

[69] Skinner R, Sharkey IM, Pearson AD, Craft AW. Ifosfamide, mesna, and nephrotoxicity in children. J Clin Oncol 1993; 11:173-190.

[70] Loebstein R, Atanackovic G, Bishai R, et al. Risk factors for long-term outcome of ifosfamide-induced nephrotoxicity in children. J Clin Pharmacol 1999;39:454-461.

[71] Oberlin O, Fawaz O, Rey A, et al. Long-term evaluation of Ifosfamide-related nephrotoxicity in children. J Clin Oncol 2009;27:5350-5355.

[72] Stöhr W, Paulides M, Bielack S, et al. Ifosfamide-induced nephrotoxicity in 593 sarcoma patients: a report from the Late Effects Surveillance System. Pediatr Blood Cancer 2007;48:447-452.

[73] Negro A, Regolisti G, Perazzoli F, Davoli S, Sani C, Rossi E. Ifosfamide-induced renal Fanconi syndrome with associated nephrogenic diabetes insipidus in an adult patient. Nephrol Dial Transplant 1998;13:1547-1549.

[74] Beckwith C, Flaharty KK, Cheung AK, Beatty PG. Fanconi's syndrome due to ifosfamide. Bone Marrow Transplant 1993;11:71-73.

[75] Farry JK, Flombaum CD, Latcha S. Long term renal toxicity of ifosfamide in adult patients--5 year data. Eur J Cancer 2012;48:1326-1331.

[76] Nissim I, Horyn O, Daikhin Y, et al. Ifosfamide-induced nephrotoxicity: mechanism and prevention. Cancer Res 2006;66:7824-7831.

[77] Yaseen Z, Michoudet C, Baverel G, Dubourg L. Mechanisms of the ifosfamide-induced inhibition of endocytosis in the rat proximal kidney tubule. Arch Toxicol 2008;82: 607-614.

[78] Linch M, Cunningham D, Mingo O, Stiles A, FarquharSmith WP. Renal tubular acidosis due to oxaliplatin. Ann Oncol 2007;18:805-806.

[79] Negro A, Grasselli C, Galli P. Oxaliplatin-induced proximal renal tubular acidosis. Intern Emerg Med 2010;5:267-268.

[80] Cachat F, Nenadov-Beck M, Guignard JP. Occurrence of an acute Fanconi syndrome following cisplatin chemotherapy. Med Pediatr Oncol 1998;31:40-41.

[81] Portilla D, Li S, Nagothu KK, et al. Metabolomic study of cisplatin-induced nephrotoxicity. Kidney Int 2006;69: 2194-2204.

[82] Nagothu KK, Bhatt R, Kaushal GP, Portilla D. Fibrate prevents cisplatin-induced proximal tubule cell death. Kid- 
ney Int 2005;68:2680-2693.

[83] Mirza N, Marson AG, Pirmohamed M. Effect of topiramate on acid-base balance: extent, mechanism and effects. $\mathrm{Br} J$ Clin Pharmacol 2009;68:655-661.

[84] Ozer Y, Altunkaya H. Topiramate induced metabolic acidosis. Anaesthesia 2004;59:830.

[85] Philippi H, Boor R, Reitter B. Topiramate and metabolic acidosis in infants and toddlers. Epilepsia 2002;43:744747.

[86] Sacré A, Jouret F, Manicourt D, Devuyst O. Topiramate induces type 3 renal tubular acidosis by inhibiting renal carbonic anhydrase. Nephrol Dial Transplant 2006;21:29952996.

[87] Recacha R, Costanzo MJ, Maryanoff BE, Chattopadhyay D. Crystal structure of human carbonic anhydrase II complexed with an anti-convulsant sugar sulphamate. Biochem J 2002;361(Pt 3):437-441.

[88] Maryanoff BE, McComsey DF, Costanzo MJ, Hochman C, Smith-Swintosky V, Shank RP. Comparison of sulfamate and sulfamide groups for the inhibition of carbonic anhydrase-II by using topiramate as a structural platform. J Med Chem 2005;48:1941-1947.

[89] Knorr M, Schaper J, Harjes M, Mayatepek E, Rosenbaum T. Fanconi syndrome caused by antiepileptic therapy with valproic Acid. Epilepsia 2004;45:868-871.

[90] Endo A, Fujita Y, Fuchigami T, Takahashi S, Mugishima H. Fanconi syndrome caused by valproic acid. Pediatr Neurol 2010;42:287-290.

[91] Shiari R, Bagherzade L, Alaei MR. Fanconi syndrome associated with valporic Acid: a case report. Iran Red Crescent Med J 2011;13:844-845.

[92] Hawkins E, Brewer E. Renal toxicity induced by valproic acid (Depakene). Pediatr Pathol 1993;13:863-868.

[93] Lenoir GR, Perignon JL, Gubler MC, Broyer M. Valproic acid: a possible cause of proximal tubular renal syndrome. J Pediatr 1981;98:503-504.

[94] Al-Bander HA, Weiss RA, Humphreys MH, Morris RC Jr. Dysfunction of the proximal tubule underlies maleic acidinduced type II renal tubular acidosis. Am J Physiol 1982; 243:F604-F611.

[95] Delea TE, Edelsberg J, Sofrygin O, et al. Consequences and costs of noncompliance with iron chelation therapy in patients with transfusion-dependent thalassemia: a literature review. Transfusion 2007;47:1919-1929.

[96] Díaz-García JD, Gallegos-Villalobos A, Gonzalez-Espinoza L, Sanchez-Niño MD, Villarrubia J, Ortiz A. Deferasirox nephrotoxicity-the knowns and unknowns. Nat Rev Nephrol 2014;10:574-586.

[97] Grangé S, Bertrand DM, Guerrot D, Eas F, Godin M. Acute renal failure and Fanconi syndrome due to deferasirox. Nephrol Dial Transplant 2010;25:2376-2378.

[98] Rafat C, Fakhouri F, Ribeil JA, Delarue R, Le Quintrec M. Fanconi syndrome due to deferasirox. Am J Kidney Dis 2009;54:931-934.

[99] Papneja K, Bhatt MD, Kirby-Allen M, Arora S, Wiernikowski JT, Athale UH. Fanconi syndrome secondary to deferasirox in Diamond-Blackfan anemia: case series and recommendations for early diagnosis. Pediatr Blood Cancer 2016;63:1480-1483.

[100] Chuang GT, Tsai IJ, Tsau YK, Lu MY. Transfusion-dependent thalassaemic patients with renal Fanconi syndrome due to deferasirox use. Nephrology (Carlton) 2015;20:931935.

[101] Lenz EM, Bright J, Knight R, et al. Metabonomics with 1H-NMR spectroscopy and liquid chromatography-mass spectrometry applied to the investigation of metabolic changes caused by gentamicin-induced nephrotoxicity in the rat. Biomarkers 2005;10:173-187.

[102] Ghiculescu RA, Kubler PA. Aminoglycoside-associated Fanconi syndrome. Am J Kidney Dis 2006;48:e89-e93.

[103] Gainza FJ, Minguela JI, Lampreabe I. Aminoglycoside-associated Fanconi's syndrome: an underrecognized entity. Nephron 1997;77:205-211.

[104] Melnick JZ, Baum M, Thompson JR. Aminoglycoside-induced Fanconi's syndrome. Am J Kidney Dis 1994;23:118122.

[105] Russo JC, Adelman RD. Gentamicin-induced Fanconi syndrome. J Pediatr 1980;96:151-153.

[106] Fleck C, Schwertfeger M, Taylor PM. Regulation of renal amino acid (AA) transport by hormones, drugs and xenobiotics-a review. Amino Acids 2003;24:347-374.

[107] Batlle D, Hays S, Foley R, Chan Y, Arruda JA, Kurtzman NA. Proximal renal tubular acidosis and hypophosphatemia induced by arginine. Adv Exp Med Biol 1982;151:239249.

[108] Lo JC, Chertow GM, Rennke H, Seifter JL. Fanconi's syndrome and tubulointerstitial nephritis in association with L-lysine ingestion. Am J Kidney Dis 1996;28:614-617.

[109] Benninga MA, Lilien M, de Koning TJ, et al. Renal Fanconi syndrome with ultrastructural defects in lysinuric protein intolerance. J Inherit Metab Dis 2007;30:402-403.

[110] Riccio E, Pisani A. Fanconi syndrome with lysinuric pro- 
tein intolerance. Clin Kidney J 2014;7:599-601.

[111] Perheentupa J, Visakorpi JK. Protein intolerance with deficient transport of basic aminoacids. Another inborn error of metabolism. Lancet 1965;2:813-816.

[112] Carpenter TO, Levy HL, Holtrop ME, Shih VE, Anast CS. Lysinuric protein intolerance presenting as childhood osteoporosis. Clinical and skeletal response to citrulline therapy. N Engl J Med 1985;312:290-294.

[113] DiRocco M, Garibotto G, Rossi GA, et al. Role of haematological, pulmonary and renal complications in the longterm prognosis of patients with lysinuric protein intolerance. Eur J Pediatr 1993;152:437-440.

[114] Parto K, Kallajoki M, Aho H, Simell O. Pulmonary alveolar proteinosis and glomerulonephritis in lysinuric protein intolerance: case reports and autopsy findings of four pediatric patients. Hum Pathol 1994;25:400-407.

[115] Houten SM, Te Brinke H, Denis S, et al. Genetic basis of hyperlysinemia. Orphanet J Rare Dis 2013;8:57.

[116] Perrone D, Afridi F, King-Morris K, Komarla A, Kar P. Proximal renal tubular acidosis (Fanconi syndrome) induced by apremilast: a case report. Am J Kidney Dis 2017;70:729731.

[117] Barbier O, Jacquillet G, Tauc M, Cougnon M, Poujeol P. Effect of heavy metals on, and handling by, the kidney. Nephron Physiol 2005;99:p105-p110.

[118] García Rodríguez JF, Sánchez-Guisande D, Novoa D, Romero R, Arcocha V. [Fanconi syndrome caused by mercury chloride poisoning]. Rev Clin Esp 1989;184:111-112. Spanish.

[119] Johri N, Jacquillet G, Unwin R. Heavy metal poisoning: the effects of cadmium on the kidney. Biometals 2010;23:783792.

[120] Gonick HC. Nephrotoxicity of cadmium \& lead. Indian J Med Res 2008;128:335-352.
[121] Rochman J, Lichtig C, Osterweill D, Tatarsky I, Eidelman S. ASdult Fanconi's syndrome with renal tubular acidosis in association with renal amyloidosis: occurrence in a patient with chronic lymphocytic leukemia. Arch Intern Med 1980;140:1361-1363.

[122] Riley AL, Ryan LM, Roth DA. Renal proximal tubular dysfunction and paroxysmal nocturnal hemoglobinuria. Am J Med 1977;62:125-129.

[123] Irizarry-Alvarado JM, Dwyer JP, Brumble LM, Alvarez S, Mendez JC. Proximal tubular dysfunction associated with tenofovir and didanosine causing Fanconi syndrome and diabetes insipidus: a report of 3 cases. AIDS Read 2009;19: 114-121.

[124] Luciani A, Sirac C, Terryn S, et al. Impaired lysosomal function underlies monoclonal light chain-associated renal Fanconi syndrome. J Am Soc Nephrol 2016;27:20492061.

[125] Woodward CL, Hall AM, Williams IG, et al. Tenofovirassociated renal and bone toxicity. HIV Med 2009;10:482487.

[126] Batlle DC, Hizon M, Cohen E, Gutterman C, Gupta R. The use of the urinary anion gap in the diagnosis of hyperchloremic metabolic acidosis. N Engl J Med 1988;318:594-599.

[127] Batlle D, Ba Aqeel SH, Marquez A. The urine anion gap in context. Clin J Am Soc Nephrol 2018;13:195-197.

[128] Kim GH, Han JS, Kim YS, Joo KW, Kim S, Lee JS. Evaluation of urine acidification by urine anion gap and urine osmolal gap in chronic metabolic acidosis. Am J Kidney Dis 1996;27:42-47.

[129] Norden AG, Lapsley M, Unwin RJ. Urine retinol-binding protein 4: a functional biomarker of the proximal renal tubule. Adv Clin Chem 2014;63:85-122.

[130] Hall AM, Bass P, Unwin RJ. Drug-induced renal Fanconi syndrome. QJM 2014;107:261-269. 